\title{
How Volunteering affects the Offender's Behavior
}

\author{
Agent-based Modelling and Simulation
}

\author{
Momina Shaheen ${ }^{1}$, Tayyaba Anees ${ }^{2}$, Muhammad Imran Manzoor ${ }^{3}$ \\ School of Systems and Technologies \\ University of Management and Technology \\ Lahore, Pakistan
}

\author{
Shuja Akbar ${ }^{4}$, Iqra Obaid ${ }^{5}$ \\ Department of Computer Science \\ COMSATS University Lahore Campus \\ Lahore, Pakistan
}

\author{
Aimen Anum ${ }^{6}$ \\ Department of Computer Science \\ COMSATS University Islamabad, Sahiwal Campus \\ Sahiwal, Pakistan
}

\begin{abstract}
Agent Based modelling is widely used for presenting and evaluating a social phenomenon. Agent based modelling helps the researcher to analyze and evaluate a social model and its related hypothetical theories by simulating a real situation. This research presents a model for showing the behavior of an offender that is greatly influenced by volunteering of people on the offending tendencies. It is observed that how the offending behavior of someone urges others to do the same criminal act or violation of norms. And how can volunteering make the offender feel shameful of his doings and motivate others to volunteer in likewise situation in future. An agent based Model is presented and simulated to evaluate and validate the conceptualization of presented social dilemma. This model is simulated by asking some questions with exacting focus on the offending behavior of an agent. This study evaluates all the simulated results from the presented model to describe theoretical foundation spreading of offending or criminal behavior. Moreover, it validates the role of volunteering in the decrement of offending tendencies of the people as it presents an understandable situation in which offending of someone increases the offending tendencies of audience. Moreover the results of this research show that the volunteering decreases the offending tendencies of not just offender but also of the audience.
\end{abstract}

Keywords-Offender's behavior; spreading of criminal behavior; agent-based modelling; simulation; norm violation; criminology

\section{INTRODUCTION}

ABM (Agent based Modeling) is a computational technique consisting of agents (autonomous decision making entities); communicating with one another in the neighborhood [1]. It directs the interaction between micro-level behavior and heterogeneous agents. Agent behavior is usually a set of rules that you need to follow to make a decision considering their interactions and environmental observations [2].

Agent based Modeling is used to perform pseudoexperiments, representing the mutual interaction and behavior of an agent. It provides the understanding of the reasons, causing the appearance a widespread phenomenon and the emergence of a variety of behavioral aspects in a population, hence validating the hypothetical fundamentals of this.
Considering these uses Agent based Modeling is an accommodating tool to study the surfacing of customs and norms in a society [3]. Agent based Modeling has been implemented in social settings to examine the various perspectives affecting the crimes [4].

In Agent base modeling, criminologist research investigates some vicious crimes like street robbery, civil violence, etc. using ABM approach [5]. To investigate spatial-temporal aspects of crime, Agent based Modeling is exercised with focus on spatial and behavioral aspects of crime. Based on diffusion of status of some places the model showed in [6] investigates the dynamics of crime places. On behavioral point, the relation among the behaviors of targets, offenders and the guardians is simulated through Agent based Modeling.

Offender makes a decision individually which assesses a situation and attempts to maximize the outcome of his actions [7][8].

In [9], the behaviors of offenders and the targets with respect to areas of crime are simulated on the basis of usual actions and theories, the fallouts of simulations are validated against actual facts. The criminologists have examined a variety of aggressive crimes like street robberies [10][11], civil violence [12][13] and gang rivalries [14]with the help of Agent based Modeling. Similarly, various research studies have also been performed on the reaction of society to a criminal activity, which keep up a correspondence to the spreading of norms in society [4]. The bystanders' effect [4], which abstain a person from volunteering against a criminal act which he observes, is another example of such situations. Some possible reasons for such a behavior diffusion of responsibility, social influence, and audience inhibition are illustrated in [4] with reference of [15]. By the presence of audience, person neglects his decision of volunteering owing to possibility of misinterpretation of the condition ensuing into an embarrassment as people do not want to disagree with the whole group [16]. In appendage to that, individuals are changed by others. When she realizes others not interceding, she also organizes alike. The third feature is also associated with the Volunteer's dilemma (VD) shown by Diekmann [17]) as It is considerable that someone volunteers, but it is best if that is not me", therefore, shifting the concern 
from own shoulders to the others. Observing these factors, it is habitually discussed that the viewer's inhibition and the social impact are values of diffusion of responsibility.

Hereafter, in some literature, the volunteer's dilemma is grasped as a result of the diffusion of responsibility, in which number of individuals in a bystanders group is inversely proportional to volunteering [18][19]. In practical conditions, the VD does not always assure negative result. People volunteer so frequently. It is proven in [18] that cooperative behavior in humans is obsessed by many characteristics of social communication, including the aspects strongly unified with the cognitive performance of guilt, like reciprocal altruism" and conflict resolution".

Guilt, ultimately, is less destructive and more adaptive [20]. Guilt is a negative value ensuing due to irregularity among the adopted and desired behavior. Hence, to get rid of guilt and act correctly, it may lead to an altruistic volunteering from a person, in conflict situations necessitating a supportive decision making. In fact, responsibility is guilt's function [21][5][22]. In other words, volunteering in the VD can be ensured, if an individual efforts to be accountable to get rid of guilt. Results of a careful investigation of the VD have exposed that 'nointervention' owed to bystanders' effect frequently approaches to guilt which, as significance, encourages the applicants to volunteer [18]. Analytical model of volunteering is not delivered in study. A model of volunteering, having supporting on three human conduct theories is presented by (Gerritsen, 2015). Though, this model shows a distinguished, but simplistic example of presentation of social theories within agent's behavior, it is limited to two dimensions. First, supports a single volunteer. Second, does not deliver any specification of offender behavior.

\section{A. Problem Statement}

Volunteering of a person is very important in the situation of norm violation as it can lead to the public good. The problem that is to be discussed in the study is when the population of people would decide to intervene in the certain situation of norm violation in the presence of the factors of a person's perception (bystanders, cost of intervention, audience inhibition, seriousness of the norm violation) and how the volunteering of a person(s) can accelerate or stop the violation themselves. And if there is a need of multiple people to intervene in a certain condition then how the situation can become. Moreover, there is a need to find the emotional effect on the people witnessing norm violation and on the offender. Does offender get ashamed when people stop him from such act of if no one volunteers and if anyone one volunteer but he is not enough to stop that act then how it will encourage or urge the offender to do that act again in future. Similarly if people who have some tendency to violate the norm or have offending tendency then to which extent they get influenced by the offender or volunteer.

\section{B. Scenario and Motivation}

Social dilemmas are the circumstances in which an individual's optimal behavior conflict with the group's optimal decision [23], in other words social dilemma is a condition in which a person prefers its self-interest unless whole population chooses the selfish option and the whole group loses. Problems occur when the whole population chooses to practice personal profit and instantaneous satisfaction rather than perform in the groups long-term. Repeated interactions which allow punishment, reciprocation and reputation effect are used to be the solution of these social dilemmas [24]. In these situation individuals can either be cooperator or defectors. A cooperator pays cost of participating in public good but defectors desist from doing so.

If a criminal activity is taking place and no one intervene or call the police then the crime won't be stopped hence the witnesses fail the victim and the moral and legal norms. Such a dilemma is called Volunteers Dilemma. The public goods are achieved when a volunteer intervene in a norm violation in order to stop the criminal activity. But if nobody volunteers then it may harm the victim of that situation. These unfortunate situations do not happen just in exercise but also in the reality such as the murder of Kitty Genovese (1964).

There are some other situations where more than one volunteers are needed to resolve a conflict. In that scenario, if there are lesser number of volunteers than needed volunteers, then the situation get totally changed as the offender(s) may feel more powerful or volunteers get disappointed. Another outcome in this scenario can be that number people who are required to volunteer may not be fulfilled but the volunteers are sufficiently enough then the offender will get ashamed over his doing or may not dare to do that again. The worst outcome of this scenario can be that if there are many observers seeing that criminal activity but no one volunteers, then the offender will have no regret or shame, moreover the people in the audience can get inspired from this situation and they can also get involved in similar situations. Hence it could lead to the spreading of dishonesty [25][26][27][6].

\section{Research Objectives}

The core objective of this research is to study the effect of volunteering on the offender and the emotional guilt in the bystanders mind by incorporating a model of volunteers in a norm violation in the field of Agent-based Modeling (ABM) that will help answer the questions mentioned in Table I.

This study will also discuss the emotional effect on the bystanders, offenders and the volunteer. This would help to understand the whole behavioral model extensively. And how these emotional effect will motivate them to do something for public good in future.

\section{TABLE I. RESEARCH QUESTIONS}

\begin{tabular}{|l|l|}
\hline No. & Research Questions \\
\hline RQ1 & $\begin{array}{l}\text { What if there are not enough volunteers that are required to stop } \\
\text { the norm violation? }\end{array}$ \\
\hline RQ2 & What is the impact lesser volunteer on the offender and people? \\
\hline RQ3 & $\begin{array}{l}\text { How can volunteering refrain offenders from violating the } \\
\text { norms? }\end{array}$ \\
\hline RQ4 & What is the emotional impact of volunteering on offenders? \\
\hline
\end{tabular}




\section{LITERATURE REVIEW}

On the area of Norm Violation and its spreading, Volunteer Dilemma, Agent-Based models, guilt and offender behavior a lot of literature is available and for this study. In this chapter a selected literature is included for understanding the area and background of the problem.

\section{A. Norm Violation and Offender Behavior in VD}

If we want to determine the reasons why norm violations took place then one reason can be that some social norm violations trigger more norm violations. For instance people don't bother to return the shopping carts if they see others doing the same. Similarly if people see an offender beating a person and no one oppose him then they can do the same in future. This reason of spreading of norm violation is also discussed in [25]. They developed an experimental design (dice experiment) to understand the dynamics between information, beliefs and co-evolution of norms by observing prevalence of norms, accuracy of beliefs and offsetting dynamics of traced social behaviors. Diekmann et al. in [28] also use this approach of Dice experiment to determine the spreading of norm violation. But [25] extended the experiment to an extent of 12 dice reports to overcome the weakness of magnitude of latter experiment. And this experiment shows that the stabilization or decay of social norms is based on the subjective beliefs of norm violation in the population.

Hill et. al. performed an empirical experiment to reveal the breaking of norm. The study presents experiment conducted to know that serving non reciprocal behavior influence individual or not. It includes experiment design which consisted of three features. First is studying behavior by iterated trust game. Second is mover's decision of reciprocity. Final is extrinsic changes to see the impact of observed behavior on personal decision making. And the hypotheses that are presented in the paper are: a) detected behavior of others has impact on behavior, b) being observed effects. The conclusion drawn in their paper are foreign shocks to observe people inspiring others to depart, thus, rewarding can benefit reciprocity.

Matthew $\mathrm{T}$ et al., investigated the supposition that a person's own self-regulation is a significant internal system that enables people to alter their behavior to follow rules [29]. They performed six studies in [29]. The first study shows whether small self-control would lift the chance that group would violate the ethical norms. It appears believable that selfcontrol allows people to behave ethically. Two studies confirm a relation among low self-control and morally wrong behavior. Entirety, two pilot studies proposed that depleted self-control might influence one to involve in immoral behavior. The purpose was to develop a decision by working and measuring consequent willingness to take moral risks. The results of this study confirmed that the decrement of self-control would result in violation of people towards social norms such that reduction would lift moral risk-taking. In second study a behavioral measure was used to measure the possibility of violating societal norms. Authors expected that small self-control would enhance the propensity to break social norms. Outcomes of this study shows that subjects with low self-control would use more swear words than the subjects with high self-control and the less self-control to the breaking the rules of societal norms. In third study, subjects finished the identical intersection of these tasks. Then subjects in favor condition received a favor, while those in the no-favor condition did not. Subjects were more expected to do a favor for the researcher when the researcher does a favor for them. They projected that reduction would decrease the chance that members would comply with norms of reciprocation. Depleted subjects failed to obey standards of reciprocity. Depletion decreased reciprocity nevertheless of if the norm was to execute or not. In fourth study the women were focused in self-control reduction condition and the words on screen were ignored. Members in the no reduction state were enquired to lookout a video as they watch usually. At the end definite that reduction would lift the chance that contestants would break up the trial regulation. Thus, selfcontrol reduction leads the participants to disobey a social regulation. In next study they assumed that the members with low self-control would inadequately follow these directions in contrast with those members that are high in trait self-control. Therefore, members with high self-control pursued the speech alteration practices additional realistically than persons with low self-control. In the final study the subjects who perform better in the Study 5 ought to track the exercise directions more devotedly than individuals who do poorer. So the subjects with low self-control practice their exercise directions less devotedly than members great in self-control. Hence, the comparative deficiencies were found self-control was connected to straight cause of breaking the social rules. Authors have recognized that obedience can develop hurtful behavior. Corporations are hard to see without obedience successfully. A weak self-control among members can pay to a weakening of the social fabric.

Another investigation to judge crime activities and lies was done in [30]. The goal of this investigation was to explore behavioral consequences of dark traits. Correlation analyses were used to investigate relation between dark traits and result variables of misconduct and high stakes lying. A sample of 464 undergraduates participants from North America (age: 16-42 yrs., males: 131, female: 333) were selected. Comprehensive Misconduct Inventory (CMI) of 58 items was used to measure tendency to involve in misconduct behaviors. CMI consisted of seven sub-scales such as Hard/Soft drug-abuse Minor/Serious Criminality, Harassing, Driving misconduct, Anti-authority misconduct. Authors used PTQL (Propensity to Lie Questionnaire) to calculate the degree to which people slot in in high stake dishonesty. They collected an online survey and the participants are asked for a self-report. And the result of this study which was collected in one hour shows that men are more engaged in misconduct than women. A positive and significant relation was found between Dark Traid variables and CMI subscales as Misconduct variables were individually regressed on 3 dark Traid variables.

The Goal Firming theory for BWT not only persuades the social rules but all legitimate rules [27]. A controlled experience was conducted to test this theory. All the subjects in experiment were at least 18 years old. For the 1 st study, the experiment was conducted in shopping area mostly used to park bicycles. Out of 77 subjects $33 \%$ were in order condition while $69 \%$ in disorder condition. The 2 nd study was conducted to determine the influence of cross norm inhibition on serious 
norms. 44 participants were in order while 49 were in disorder condition. In 3rd study, the participants who returned the shopping carts ere in order while the others who don't were in disorder. The results of study three shows that $30 \%$ were in order and $58 \%$ were in disorder condition. 4th study focused on national law of fireworks and the $80 \%$ subjects were found in disorder condition. 5th and 6th study were based on stealing an envelope with $€ 5$ note was placed in mailbox. 5th study includes 60 participants and the mailbox was not covered but in study six participants were 72 and the mailbox was covered with graffiti. $13 \%$ were in order condition in 5th study and $25 \%$ in 6th study stole the envelop. Conclusions revealed that the effect was not restricted to social norms.

Gino et al. conducted two experiments to examine how social norms, saliency and cost benefit analysis encourage immoral behavior. In first experiment they examine the influences of confederate's identity [31]. Their laboratory experiment includes four conditions; a) control condition, b) shredder condition, c) in-group identity condition, and d) out-group identity condition. One hundred forty-one (79 male, 62 female) subjects with average age of 22 years participated in the experiment. The results revealed that subjects in the control condition showed the minimum number of properly solved matrices. Cheating in the shredder condition was raised by more than $50 \%$. Cheating raised more in the ingroup-identity condition and reduced in the out-group-identity condition. Their second experiment was conducted to determine the effects of saliency. It includes three conditions: a) control condition, b) the shredder condition and c) the saliency condition. Ninety-two pupils (49 male, 43 female) with average age of 20 years took part in this experiment. 15 to 17 subjects were assigned randomly to each of six sessions lasting 15 minutes. Results showed that number of matrices solved was lesser in control condition, greatest in shredder and intermediate in saliency condition. So they reach to the conclusion that effect of social norms can cause higher dishonesty if the saliency were reduced.

\section{B. Use of Agent Based Models for Social Phenomena}

Agent based modeling is vastly used technique and it is being popular now a days for computing and Artificial Intelligence (AI) [32]. Agent based modeling is used not only in computing and engineering field but also in a number of fields like Social Sciences, Bio Informatics, Life Sciences, Ecological Sciences, etc. [33][34][35]. In fact, for the scheduling and planning of manufacturing process the agent based techniques are used in [36][37]. Similarly it is used for simulating social actions [38] [39]. Because through ABM the hypothesis related to these fields can be tested empirically [40].

Somehow, the techniques of agent based modeling need some improvements that are discussed by Heath in [41] as well as it faces some challenges [42] [32]. But for the phenomena of social sciences it is quite appropriate to use existing techniques as it has been used since two decades. The complex phenomenon and social patterns are modeled by agent based tools [42]. However the techniques use some implicit methodological protocols and need a refined pattern for simulating social phenomenon. In [43], the authors introduced a three staged process for the establishment of this methodology.
Lemos et al. used Agent based Model of Epstein from civil violence against an authority with the agents "citizen" and "cops" to introduce the legitimacy feedback and to examine its effects [12]. They formulated some functions on the basis of legitimacy measurement to express the legitimacy in terms of variables consumed by the model. Two type of feedbacks they used, homogeneous (all agents have same perception) and heterogeneous (agents have different perceptions) perceived legitimacy. They found that in homogeneous legitimacy distant future performance of the system was unspecified but for diverse the time evolution of the system was initially calm then rebellion and after that successively intermittent peaks of rebellion. Their results represented significant improvement from their previous work in the aspect of soundness, explanatory power and simplicity.

Crime behavior changes with the advancement of technology hence in [44] authors argued that in crime fighting arsenal, mathematical models are valuable weapons. They discussed different techniques for crime fighting such as mathematical models numerical simulations, differential equations and agent based models with some empirical evidences and statistics. They reached to the conclusions that a multi-disciplinary approach is needed to build a model for crime. They proposed that multi-disciplinary approach can be division of work among sociologists, mathematicians and statisticians as the theory would be formulated by sociologists, mathematicians build a mathematical model and the statisticians made tools for the estimation of that model.

On the basis of reviewed literature the enough related information regarding to the area of the problem has been extracted. In the light of the literature it can be seen that there is some space of experimenting the multiple volunteering in the Volunteer's Dilemma, as this topic is always remained unfocused. Moreover, the guilt and shame is also discussed in norm violation and in this area of VD this can be implemented to find the positive outcomes (if any) on the Volunteering. The Offender is the one who offend, it can be seen that the offending and norm violating had bad impact on a society but how these can be controlled and how they affect the people. The spreading of dishonesty and crime are discussed in the literature, it can be find out if the volunteering or volunteering can play a role in this issue.

\section{Methodology}

This study aims to present the extended model of bystander effect presented in [4] to support the multiple interventions of the people in a certain situation where multiple interventions are needed. Guilt has a positive effect in the situation of Volunteer Dilemma. The model also incorporate the guilt of an individual that is the result of his/her own past experience as the booster to enhance the threshold so that individual have more tendency to volunteer. This research uses Model methodology in which the norm violation and the volunteer's dilemma (described in [17]) is presented with the help of the model depicting the situation. The model will be created and analyze through the ABM (agent-based modeling). The model will be tested in different scenarios, generated by the variations in the values of the factor affecting the crime situation. Data will be generated from those simulations by changing the 
values of variables. These data gathered under different values of variables will be compared to reach some conclusions. This data will enable to find out the behavior and the emotional belief of the bystanders, volunteers and the offender. And we will see if the volunteering would avoid doing the offender from doing such norm violation or not. As long as the literature supports this methodology, testing procedure of this study is influenced by (Gerritsen, 2015). After seeing the effect of guilt on the agent that guilt is a positive factor to increase the volunteering tendency in an agent. There is a thought of seeing that what is the effect of volunteering on offender (norm violator) through embarrassment or realization of wrong doing? This will involve some effects from bystanders if the ratio of number of volunteer required and number of volunteers that actually volunteer is less than 1 it means not enough volunteer participated then number of volunteer will be compared with the number of bystanders. So we can say that either shame or urge of offending will be calculated by comparing the volunteering from two factors of required volunteer and bystanders.

Another model is described in this study that represent the behavior of the offender on volunteering and the effect of offending of someone on the other people who are seeing him doing that norm violation. This model is based on the spreading of criminal activities due to non-volunteering of people over norm violation. It represents a good platform to show that how offending tendency of people increased or decreased.

\section{A. Offender Behavior Model}

There are some evidences from the literature that if someone is involved in a criminal activity and no one took any notice against him then he is a source of encouraging others who have a tendency to do criminal activity [25][27][6]. Some field experiments shows that if some people don't return shopping carts or do illegal parking then others also get involved in doing the same activity [18]. This is how the dishonesty and wrong-doings spread with higher ratio among the people if everyone decides to be silent [26].
In this model (shown in Fig. 1) the offending tendencies of agents are calculated. In the start there is only one offender and then population increases gradually. The "Offending Tendency" rate is randomly selected for each agent from $\mathbf{0 . 1}$ to 0.9. Another constant is introduced in this model, k-constant; this constant is assigned different values on the basis beliefs and desires of the agents.

At the start the agent will observe the number of bystander (n) and the number of volunteer (m) and the Offending Tendency OT is randomly assigned to every agent. Here 37 the number of required volunteers $(\mathbf{v})$ is also determined to have ratio of actual volunteers and required volunteers (i.e. $\mathbf{m} / \mathbf{v}$ ). There are two cases that will run through this model are:

CASE 1: If the ratio of volunteers and required volunteer is less than 1 (i.e. $\mathbf{m} / \mathbf{v}<\mathbf{1}$ ) then;

a) If Offending Tendency (randomly assigned) is greater or equal to the ratio of volunteers and required volunteers ( i.e. OT $>=\mathbf{m} / \mathbf{v}$ ), then that particular agent will have desire to offend more and the value of k-constant will be given as -4 (i.e. $\mathbf{k}=-4)$.

$b$ ) If Offending Tendency is less than the ratio of volunteers and required volunteers (i.e. OT $<\mathbf{m} / \mathbf{v}$ ), then the agent will have a desire to help due to the embarrassment and the $\mathrm{k}$ will be assigned the value ' 4 ' in this particular situation.

CASE 2: If the ratio of volunteers and required volunteer is greater or equal to 1 (i.e. $\mathbf{m} / \mathbf{v}>=\mathbf{1}$ ) then;

a) If Offending Tendency is greater or equal to the half of the ratio of volunteers and required volunteers (i.e. OT >= $1 / 2(\mathbf{m} / \mathbf{v}))$, then the agent will have desire to relax some OT and the k-constant will be assigned by the value 2 (i.e. $\mathbf{k}=2$ )

b) If Offending Tendency is lesser than the half of the ratio of volunteers and required volunteers (i.e. OT < $1 / 2(\mathbf{m} / \mathbf{v}))$, then the agent will have increased motivation to help the victim and the $\mathrm{k}$-constant will be assigned by the value 2 (i.e. $\mathrm{k}=1$ ).

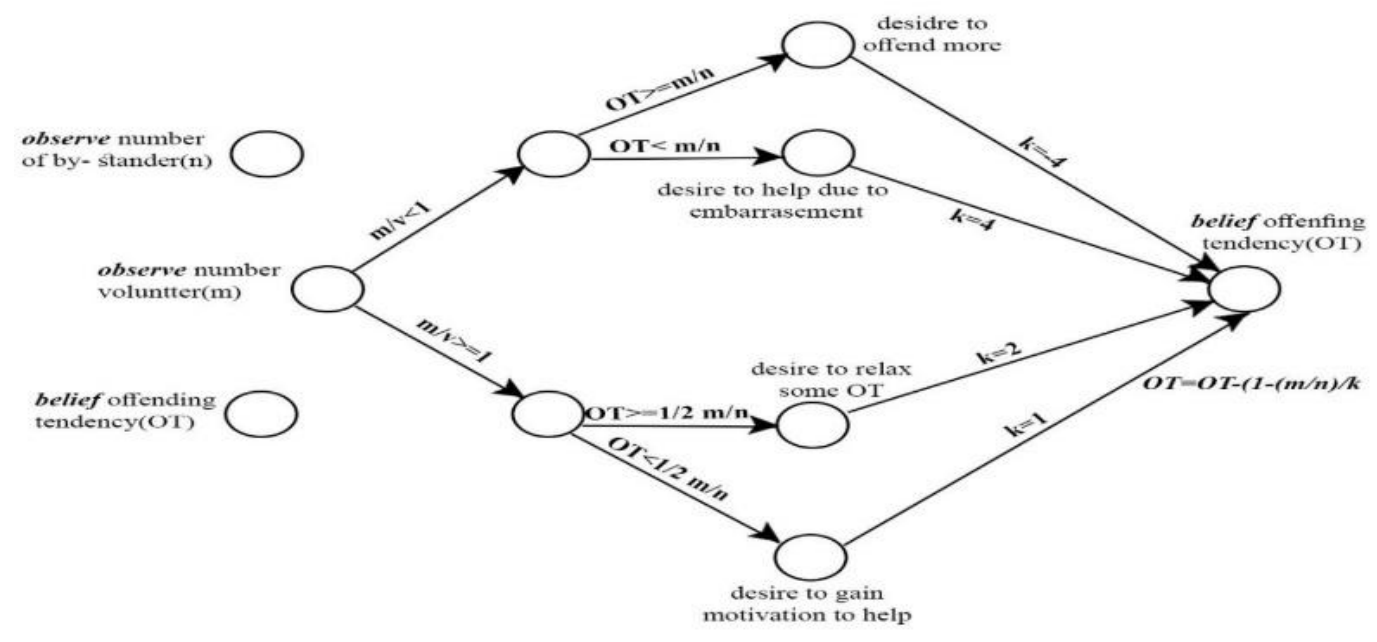

Fig. 1. Offender's Behavior Model. 
At the end, for each case the value of Offending tendency is calculated on the basis of the values of ' $\mathbf{k}$ ' and ' $\mathbf{m} / \mathbf{v}$ ' gained by each case separately through this formula OT= (OT- (1$(\mathbf{m} / \mathbf{n}) / \mathbf{k})$. this will be the solid value of OT, calculated for each agent separately, and this OT will be used for the next iteration.

\section{IMPLEMENTATION}

In this study two models are presented in previous chapter the extended bystanders model and the model of offender behavior. These two models are needed to be implemented in some environment to examine the behavior of people. Examining these models there can be some hypotheses that are drawn on the basis of the research questions. Sometimes applying a situation on real environment and real people get a lot of time and attention as well as people perform artificially in such experiments so it lead to inaccurate results. It is nearly impossible to study all the people in the situation individually. Moreover, these types of experiments can lead the participants in real hazards. To get the results of our model with the absence of these issues the simulated environment are used.

\section{A. Hypotheses}

The following hypotheses can be drawn from the models on the basis of Research Questions shown in Table I.

H1. If there will be no volunteer or lesser than the required volunteers, which are required to achieve public good then the offending tendency of the offender would be increased.

H2. If there is sufficient volunteering to refrain the offenders from violating the norm then the offending tendency of the offender would be decreased and he will be shameful over his act.

H3. In the case of no-volunteering or minor volunteering the offending tendency of the others will also be increased (seeing that no punishment is given to the offender, the bystander will urge to violate that norm)

H4. If there will be sufficient volunteering then the not only the offender but also the bystanders will decrease their offending tendency.

To testify these hypotheses the model must be implemented on some simulated environment to get the accurate and precise results.

\section{B. Simulation}

In this study simulations are used to implement the presented models. Simulations are very appropriate for practicing this model as simulation techniques are used to implement the real environment situation in which getting results and doing analysis is difficult. Simulation is used to avoid expensive prototyping, testing, sensitive systems which are not able to bear extensive tests and performing experiments on real system is not possible because experiments are much time consuming than simulations (Rossetti et al. 2009). These Value, Time, Accuracy, Visibility and Versatility simulate real life without any effect on real objects.

There are many simulations tools that can be used to simulate the environment required for this research. But the model that is used for this study is NetLogo. NetLogo is a tool used for simulating a real environment of a complex phenomenon with multiple agents. This programmable tool is capable of creating and simulating the behavior of multiple agents, event hundreds of agents can be simulated (Tisue and Wilensky, n.d.). This agent based simulating tool is helpful for simulating phenomenon of social sciences (Madey 2009).

\section{Types of Agents}

Several types of agents are used to simulate this complex phenomenon. These are the types of agents with descriptions

1) Observer: Observer is an agent who is observing the criminal act and thinking about whether he should intervene or not on the basis of his beliefs and desires. Observer agents are distinguished by Green color.

2) Bystander: Those agents who are present at the place where a norm violation is happening. These agents are distinguished by Blue color.

3) Offender: The agent who is violating a certain norm. Offender is distinguished by color Red and shape of a bug.

4) Volunteer: The agent who feels himself personally responsible and capable to do the intervention to stop the offender from violating the norm. Agent who has volunteered is distinguished by the grey color.

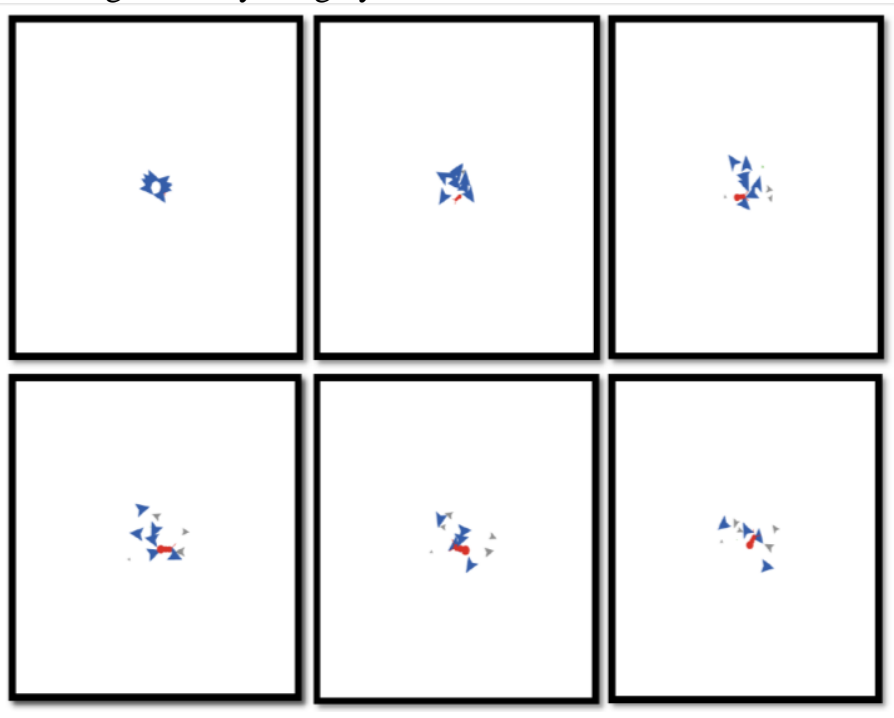

Fig. 2. Simulations Representing the Agents in a Controlled Environment.

\section{Scenarios}

In this study different scenarios taken for the execution of this model in order to fetch the results required for the validation of these hypothesis. These scenarios are taken on the basis of population with some variables described below:

1) Offending tendency: This variable is randomly assigned to each agent from 0.1 to 0.5 . The offender is assigned with relatively high offending tendency.

2) Desire of intervention: A Boolean variable set true the value of accumulated variable ' $x$ ' is greater than the value of norm (normality).

3) Capability: A Boolean variable set true if the observer feels himself capable of doing the intervention. 
4) Intention: A Boolean variable set true if the observer have desire to intervene AND feels himself capable of doing intervention.

5) $K$ : is a constant value assigned on the basis of the desire of an agent to offend.

These were the significant variable used to implement this model on NetLogo. The whole model that is implemented in the NetLogo is described in the next chapter through ODD Protocol.

\section{AgENT BASED DESCRIPTION USING ODD PROTOCOL}

The ODD model (Overview, Design, Detail, described by (J. Gary Polhill 2008)) is used describe a model to enhance its completeness and readability of the model.

\section{A. Overview}

This Model is designed to present the volunteers' dilemma along with the offender behavior in which the guilt is incorporated with the multiple interventions of volunteering.

In this section the overview of the model that is implemented in Netlogo is presented by the terms of purpose of the model, state variables and process scheduling.

\section{B. Purpose}

The purpose of this model is to find the effect of guilt on the volunteering tendency of the agent and the effect of volunteering on the offending tendency of people and offender. If there are more bystanders the ratio of volunteering would be lesser due to increased audience inhibition and cost of intervention. Hence, the rate of volunteering and the number of bystanders are inversely proportional to each other. The model describes the phenomenon of spreading of norm violation by offending tendencies of people. And how the volunteering can reduce the spreading of these norm violations?

There are some factors in such phenomenon. The thresholds of seriousness (due to abnormality of the situation or the accumulated guilt of the observer from past experiences) then the observer will find him more responsible. The offending tendency of the offender would be increased if the volunteers will be lesser. The offending tendency of the offender would be decreased and he will be shameful over his act due to volunteering. If there will be sufficient volunteering then the not only the offender but also the bystanders will decrease their offending tendency. To testify these hypotheses the model must be implemented on some simulated environment to get the accurate and precise results.

\section{State Variables and Scale}

This model contains a large number of variables used to implement this model. Those variables with their brief descriptions are enlisted in Table II.

There are certain characteristics owned by the agents who exist in the current phenomenon. These characteristics are variant in the whole phenomenon. The BDI model is used as theoretical framework to describe the change in sensing of the agents. These characteristics are shown in Table III.
As the BDI model is used for this purpose to represent the beliefs, desire and interventions of an agent. The same agent may have different beliefs on how the situation is getting changed. So the various belief variables can be assigned to one agent, which are assigned by their corresponding values, as mentioned in Table IV.

As the belief of an agent get changed. Similarly, the agents have different desires on how the situation is getting changed and the variables of desire can be assigned according to their corresponding values. The properties of Desire of an agent are given in Table $\mathrm{V}$.

All the phenomenon of Offenders bahvior is implemented in Netlogo for the simulation study of given agents (as shown in Fig. 2).

TABLE II. VARIABLE USED IN OFFENDER BEHAVIOR MODEL

\begin{tabular}{|l|l|}
\hline Variable & Brief Description \\
\hline agents \{property: bystander\} & $\begin{array}{l}\text { The agents which will play the role of } \\
\text { bystanders in the model. }\end{array}$ \\
\hline agents \{property: offender\} & The agent who is violating a norm. \\
\hline aggregate-off-tendency & $\begin{array}{l}\text { Global variable. It shows the total } \\
\text { accumulated offending tendency of the } \\
\text { agents existing in the situation. }\end{array}$ \\
\hline count-interveners & $\begin{array}{l}\text { Global variable. Count the total number of } \\
\text { interveners/volunteers }\end{array}$ \\
\hline count-performed & $\begin{array}{l}\text { Global variable. Count the total number of } \\
\text { interventions. }\end{array}$ \\
\hline current-intervener & $\begin{array}{l}\text { Global variable. The agent who is } \\
\text { volunteering currently }\end{array}$ \\
\hline
\end{tabular}

TABLE III. CHARACTERISTICS OF AN AGENT

\begin{tabular}{|l|l|}
\hline $\begin{array}{l}\text { Characteristic } \\
\text { Variable }\end{array}$ & Brief Description \\
\hline property & $\begin{array}{l}\text { Shows the type of the agent whether it's a bystander } \\
\text { or offender etc. }\end{array}$ \\
\hline state & Describe the state or current action of an agent \\
\hline observe & Determine what the agent observes. \\
\hline
\end{tabular}

TABLE IV. BeLIEF PRoperty of AN AgENT

\begin{tabular}{|l|l|}
\hline Belief properties & Brief Description \\
\hline "Resource" & Boolean variable. \\
\hline "capable" & Boolean variable. \\
\hline "opportunity-for" & Boolean variable. \\
\hline
\end{tabular}

TABLE V. DESIRE PROPERTY OF AND AGENT

\begin{tabular}{|l|l|}
\hline Desire Properties & Brief Description \\
\hline "intervention" & $\begin{array}{l}\text { Boolean variable. Set true if the agent has desire to } \\
\text { intervene. }\end{array}$ \\
\hline $\begin{array}{l}\text { "no-need-of- } \\
\text { intervention" }\end{array}$ & $\begin{array}{l}\text { Boolean variable. Set true if the agent doesn't have } \\
\text { desire to intervene. }\end{array}$ \\
\hline
\end{tabular}




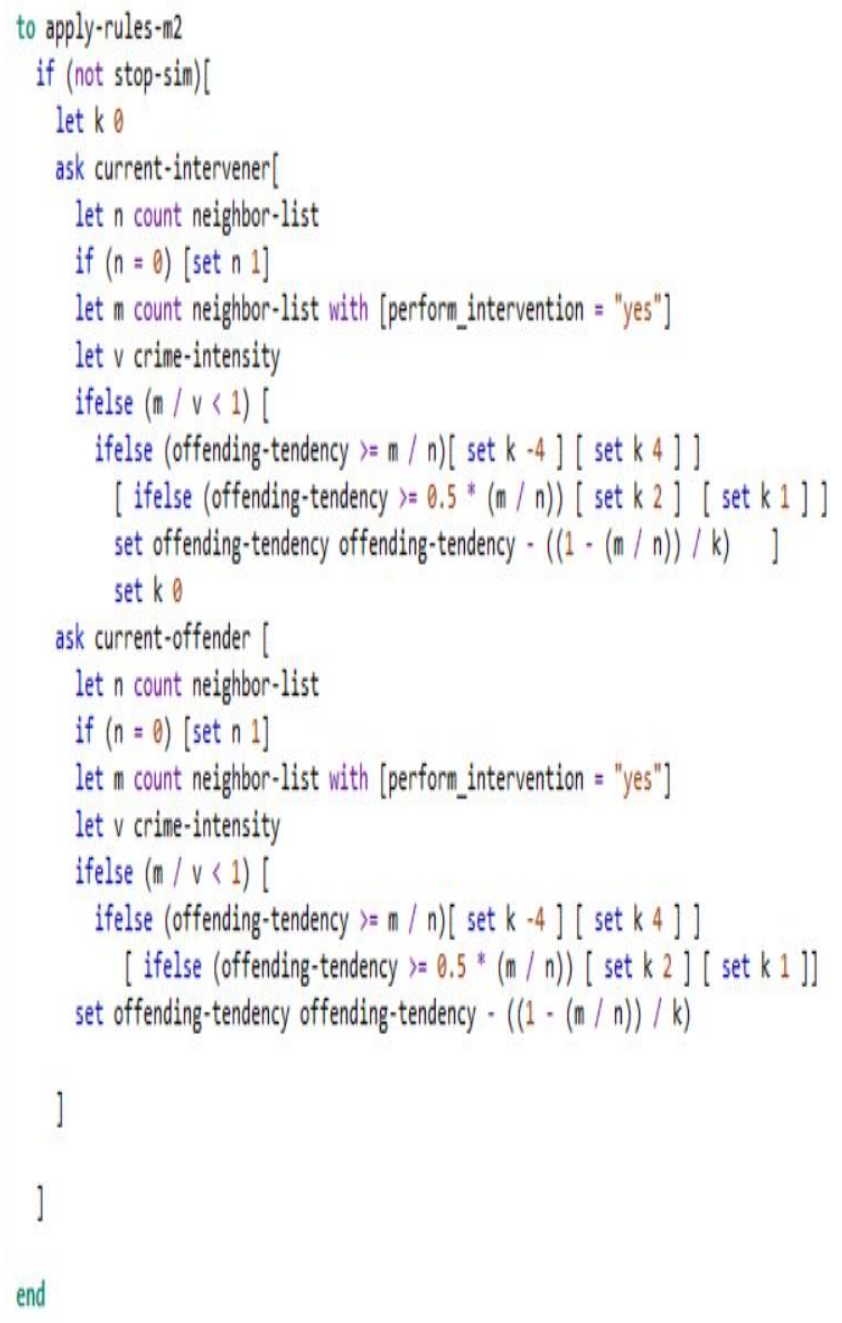

Fig. 3. Applying the Rules of Offender behavior Model in Netlogo.

\section{Process Overview and Scheduling}

In start the agents are created and the variables are initialized. The roles of the agent are assigned as offender or bystanders along with their random offending tendencies.

Then the seriousness is calculated on the basis of input variables. Then the agents walk and their roles get changed according to their sensing. The bystander agent can or cannot be the observer in next time and update its neighbor list. Then the rules of model 1 and model 2 are implemented. In the end for the refined output the graphs are drawn. This process scheduling of this model is simple and the scheduling and flow of processes in the model can be distinguished by a simple flow chart, given in Fig. 4. A chunk of code in Fig. 3 represents the rules of Offender's Behavior Model applied in NetLogo.

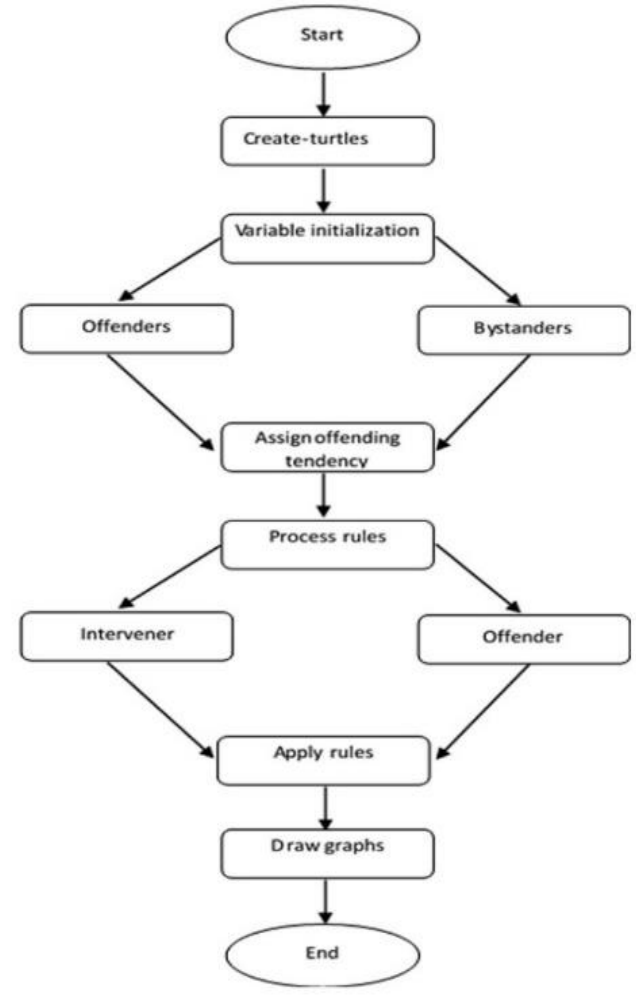

Fig. 4. Process Flow of the Whole Offenders Model used with Bystander's Model.

\section{SimUlation ANALYSIS AND RESUlts}

This Chapter shows the results fetched from the simulations that are run for some scenarios of the models.

\section{A. Simulation Analysis}

The implementation of this model is run for the 243 scenarios initially. Some of the interesting scenarios that answer the questions of our hypothesis are listed in Table VI below.

1) Case 1: In this case people are volunteering to achieve public good. People have a desire to intervene, so people are volunteering to stop this norm violation and the person who is violating this norm get ashamed over his doing and he can relaxes some offending tendency that is why the offending tendency is gradually decreasing. This case validates the hypotheses $\mathbf{H 2}$.

2) Case 2: More number of agents are required to volunteer and the situation is intense and serious, that's why the people volunteer and it lessen the offending tendency of the offending agent to 1.5 (as shown in Fig. 5(a) and Fig. 5(b)). This case validates the hypotheses $\mathbf{H} \mathbf{2}$ and $\mathbf{H 4}$. 
3) Case 3: This is an interesting case depicting the effect of volunteering on offender. People are volunteering and we can see that the offending tendency of the agent has decreased to '0' (as shown in Fig. 5(c)) Therefore, he is not offender anymore (as shown in Fig. 5) that the offender has disappeared). This is because of increasing volunteering of the people (shown in Fig. 5(b)). This case testifies the hypotheses $\mathrm{H} 2$ and $\mathrm{H} 4$.

\section{B. Results}

After analyzing the cases and running the phenomenon with a large number of scenarios, the analysis of the whole problem can be done. The analyses were enough to answer all the research questions shown in Table I.

The scenarios, presented in the dissertation, satisfy all the hypotheses. And represent the volunteering can reduce the offending behavior among people. In all the cases where volunteering is performed the ratio of offending tendency decreases. Moreover it can also be seen that in more than $50 \%$ cases the offending tendency does not reduce due to no or lesser volunteering.

TABLE VI. SOME INTERESTING CASES

\begin{tabular}{|l|l|l|l|}
\hline Cases & No of total Agents & $\begin{array}{l}\text { Crime Intensity/Required } \\
\text { No. of volunteers }(\boldsymbol{v})\end{array}$ & Radius \\
\hline 1 & 4 & 2 & 5 \\
\hline 2 & 4 & 3 & 5 \\
\hline 3 & 12 & 1 & 5 \\
\hline
\end{tabular}
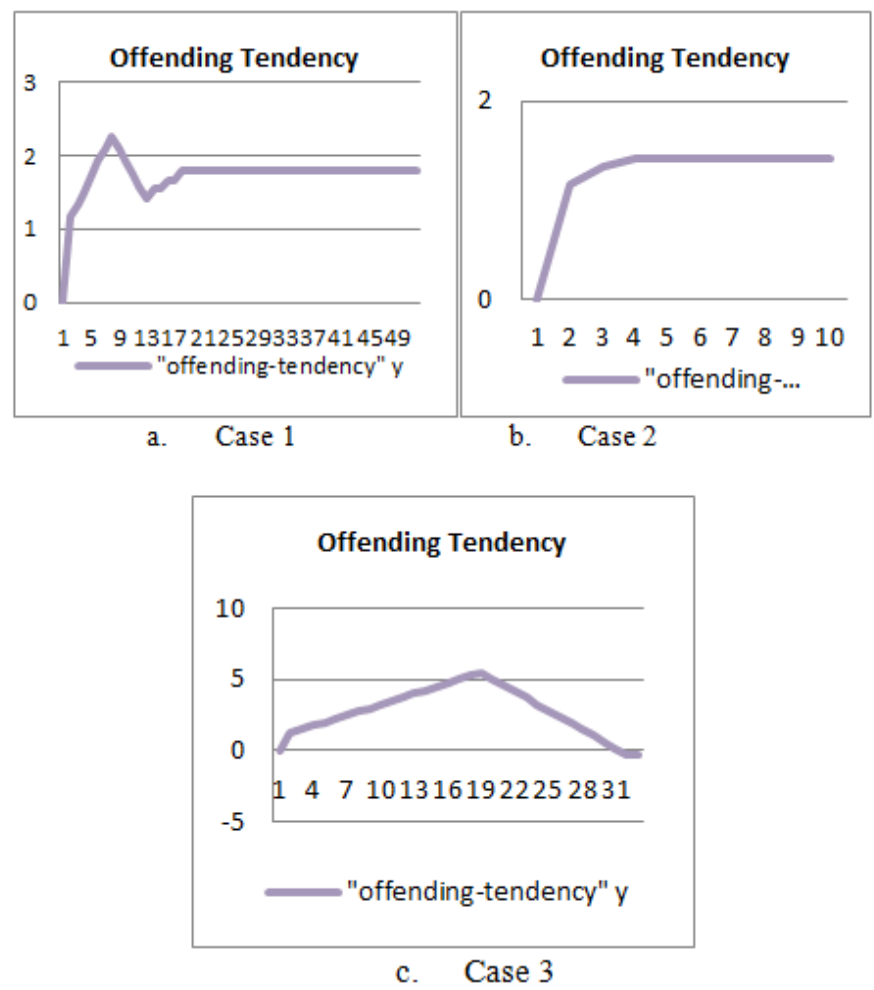

Fig. 5. How Offending Tendency of the Agents Changes for Each Case.
Researcher and scholars have done a lot of work in this area of volunteering dilemma and presented different models of volunteering guilt and offender behavior. Agent-based modeling was also used by the researchers to present the behavior of agents in this situation of volunteering dilemma but the scenario of multiple volunteering was not as much focused as needed. These aspects add some interesting changes in the ratio of volunteering.

Another important contribution of this study is related with the behavior of offender and the effect of offending and nonvolunteering on other persons. This study describes that through volunteering, offender get ashamed and its tendency of offending relaxes. But if there is no intervention from the observers of the crime act then he might not get ashamed and he will have urge to offend more. Moreover, this nonvolunteering can urge other to do the same norm violation as they get influenced by the offender. In this way this research presents a reason of spreading of norm violation.

In practice, this research will be useful for observing the criminal behavior among people and to define new ways of investigating the ways these violations crimes can be reduced. Some ways have been described in this research such as practicing the ways which are significant to increase volunteering and the others are shame and guilt.

\section{CONCLUSION}

The models presented in this research are agent based model representing a) the effect of offender's behavior on the others and on society, $b$ ) the volunteering as a factor to reduce offending behavior among people, in a crime situation. The presented model is formulated by using the outcomes of gametheoretic experiments, done on the VD.

The model is an extension of the models presented in (Lemos, Coelho, and Lopes, n.d.) and (Zia et al. 2016), and shares the similar results. It is drawn from results of this repetitive game that if the thresholds of seriousness (guilt is added in this) are increased then the participation of people in volunteering is increased. The observer in crime situation influenced by the audience and does not volunteer either due to the fear of embarrassment or due to diffusion of responsibility. The research study also validates the guilt as positive factor to increase the threshold, hence, increasing the tendency of a person to volunteer. This study elaborates the positive effect of volunteering upon the offending of a person or society. The results shows that the volunteering of people cause embarrassment to the offender and he would avoid offending afterwards.

\section{CONTRIBUTIONS}

Norm Violation, Volunteer Dilemma and Offending behavior are not new in the field of social sciences, a huge literature can be found on this area, presenting the different dimensions of volunteer Dilemma and different aspects of increasing the volunteering. Researchers have also studied the different factors affecting these issues such as, effect of bystanders, diffusion of responsibility, guilt, influence of people etc. (Zia et al. 2016). This research study is an attempt 
to represent a model that elaborates how the Volunteering brings good in a society through decreasing the ratio of offending. If the offending ratio is increased then the spreading of the criminal behavior would be initiated and the society could suffer. In this research all the factors that can help to reduce the offending tendency are discussed.

\section{REFERENCES}

[1] G. N. Gilbert and Sage Publications., Agent-based models.

[2] T. R. Caskey, J. S. Wasek, and A. Y. Franz, "Deter and protect: crime modeling with multi-agent learning," Complex Intell. Syst., pp. 1-15, Oct. 2017.

[3] A. Diekmann and W. Przepiorka, “'Take One for the Team!' Individual Heterogeneity and the Emergence of Latent Norms in a Volunteer's Dilemma," Soc. Forces, vol. 94, no. 3, pp. 1309-1333, Mar. 2016.

[4] C. Gerritsen et al., "Agent-based modelling as a research tool for criminological research," Crime Sci., vol. 4, no. 1, p. 2, Dec. 2015.

[5] K. Zia, M. Shaheen, U. Farooq, and S. Nazir, Conditions of depleting offender behavior in volunteering dilemma: An agent-based simulation study, vol. 9825. 2016.

[6] T. Bosse and C. Gerritsen, "Social Simulation and Analysis of the Dynamics of Criminal Hot Spots," J. Artif. Soc. Soc. Simul., vol. 13, no. 2, p. 5, 2009.

[7] R. R. Brüngger, C. Kadar, and I. P. Cvijikj, "Design of an Agent-Based Model to Predict Crime (WIP)," SummerSim-SCSC, 2016.

[8] D. B. (Derek B. Cornish and R. V. G. Clarke, The reasoning criminal : rational choice perspectives on offending.

[9] L. Liu, X. Wang, J. Eck, and J. Liang, "Simulating Crime Events and Crime Patterns in a RA/CA Model," in Geographic Information Systems and Crime Analysis, IGI Global, 1AD, pp. 197-213.

[10] E. R. Groff, "?Situating? Simulation to Model Human Spatio-Temporal Interactions: An Example Using Crime Events," Trans. GIS, vol. 11, no. 4, pp. 507-530, Aug. 2007.

[11] E. R. Groff, "Simulation for Theory Testing and Experimentation: An Example Using Routine Activity Theory and Street Robbery," J. Quant. Criminol., vol. 23, no. 2, pp. 75-103, Mar. 2007.

[12] C. Lemos, R. J. Lopes, and H. Coelho, "On Legitimacy Feedback Mechanisms in Agent-Based Modeling of Civil Violence," Int. J. Intell. Syst., vol. 31, no. 2, pp. 106-127, Feb. 2016.

[13] C. Lemos, H. Coelho, and R. J. Lopes, "Agent-based modeling of social conflict, civil violence and revolution: state-of-the-art-review and further prospects.

[14] R. A. Hegemann, L. M. Smith, A. B. T. Barbaro, A. L. Bertozzi, S. E. Reid, and G. E. Tita, "Geographical influences of an emerging network of gang rivalries," Phys. A Stat. Mech. its Appl., vol. 390, no. 21-22, pp. 3894-3914, Oct. 2011.

[15] B. Latan? and S. Nida, "Ten years of research on group size and helping.," Psychol. Bull., vol. 89, no. 2, pp. 308-324, 1981.

[16] F. Hoffmann, "Disliking to disagree," pp. 1-68, 2017.

[17] A. Diekmann, "Volunteer's Dilemma," J. Conflict Resolut., vol. 29, no. 4, pp. 605-610, Dec. 1985.

[18] Guillaume De, "Guilt Aversion in the Volunteer's Dilemma," 1928.

[19] P. R. Heck and J. I. Krueger, "Running head: SOCIAL PERCEPTION AND OUTCOME BIAS In press:," no. 401.

[20] J. P. Tangney, J. Stuewig, and L. Hafez, "Shame, guilt, and remorse: implications for offender populations," J. Forens. Psychiatry Psychol., vol. 22, no. 5, pp. 706-723, Oct. 2011.

[21] "ResearchGate."[Online].Available: https://www.researchgate.net/publication/230026124_On_the_relationsh ip_between_responsibility_and_guilt_Antecedent_appraisal_or_elaborat ed_appraisal.
[22] C. Bellemare, A. Sebald, and S. Suetens, "Heterogeneous guilt aversion and incentive effects," no. August, 2013.

[23] M. ARCHETTI, "Cooperation as a volunteer's dilemma and the strategy of conflict in public goods games," J. Evol. Biol., vol. 22, no. 11, pp. 2192-2200, Nov. 2009.

[24] R. Conte, M. Paolucci, and F. Cecconi, "Trends in Social Science: The Impact of Computational and Simulative Models," in New Frontiers in the Study of Social Phenomena, Cham: Springer International Publishing, 2016, pp. 145-152.

[25] H. Rauhut, "Beliefs about lying and spreading of dishonesty: undetected lies and their constructive and destructive social dynamics in dice experiments.," PLoS One, vol. 8, no. 11, p. e77878, 2013.

[26] F. Gino, S. Ayal, and D. Ariely, "Contagion and Differentiation in Unethical Behavior: The Effect of One Bad Apple on the Barrel," Psychol. Sci., vol. 20, no. 3, pp. 393-398, Mar. 2009.

[27] K. Keizer, S. Lindenberg, and L. Steg, "The Spreading of Disorder," Science (80-. )., vol. 322, no. 5908, pp. 1681-1685, Dec. 2008.

[28] A. Diekmann, W. Przepiorka, and H. Rauhut, "Lifting the veil of ignorance: An experiment on the contagiousness of norm violations," Discuss. Pap., 2011.

[29] M. T. Gailliot, S. A. Gitter, M. D. Baker, and R. F. Baumeister, "Breaking the Rules: Low Trait or State Self-Control Increases Social Norm Violations," Psychology, vol. 3, no. 12, pp. 1074-1083, 2012.

[30] N. Azizli et al., "Lies and crimes: Dark Triad, misconduct, and highstakes deception," Pers. Individ. Dif., vol. 89, pp. 34-39, Jan. 2016.

[31] N. J. Raihani and R. Bshary, "The Evolution of Punishment in N-Player Public Goods Games: A Volunteer's Dilemma," Evolution (N. Y)., vol. 65, no. 10, pp. 2725-2728, Oct. 2011.

[32] M. Wooldridge and N. R. Jennings, "Agent theories, architectures, and languages: A survey," Springer Berlin Heidelberg, 1995, pp. 1-39.

[33] M. Niazi and A. Hussain, "Agent-based computing from multi-agent systems to agent-based Models: a visual survey," Scientometrics, pp. 121, 2011.

[34] V. Rai and A. D. Henry, "Agent-based modelling of consumer energy choices," Nat. Clim. Chang., vol. 6, no. 6, pp. 556-562, 2016.

[35] M. Sajjad, K. Singh, E. Paik, and C.-W. Ahn, "A Data-Driven Approach for Agent-Based Modeling: Simulating the Dynamics of Family Formation," J. Artif. Soc. Soc. Simul., vol. 19, no. 1, 2016.

[36] Weiming Shen, Lihui Wang, and Qi Hao, “Agent-based distributed manufacturing process planning and scheduling: a state-of-the-art survey," IEEE Trans. Syst. Man Cybern. Part C (Applications Rev., vol. 36, no. 4, pp. 563-577, Jul. 2006.

[37] P. Leitão, "Agent-based distributed manufacturing control: A state-ofthe-art survey," Eng. Appl. Artif. Intell., vol. 22, no. 7, pp. 979-991, 2009.

[38] K. Narasimhan, T. Roberts, M. Xenitidou, and N. Gilbert, "Using ABM to clarify and refine social practice theory," Adv. Intell. Syst. Comput., vol. 528, pp. 307-319, 2017.

[39] C. Castelfranchi, "Modelling social action for AI agents," Artif. Intell., vol. 103, no. 1, pp. 157-182, 1998.

[40] R. B. and F. Squazzoni, "Does Empirical Embeddedness Matter? Methodological Issues on Agent-Based Models for Analytical Social Science," 2005.

[41] R. H. and F. C. Brian Heath, "A Survey of Agent-Based Modeling Practices (January 1998 to July 2008)," 2009.

[42] J. Pavón, M. Arroyo, S. Hassan, and C. Sansores, "Agent-based modelling and simulation for the analysis of social patterns," 2008.

[43] M. G. Richiardi, R. Leombruni, N. J. Saam, and M. Sonnessa, "A Common Protocol for Agent-Based Social Simulation.

[44] J. Sooknanan, B. Bhatt FIMA, and D. M. Comissiong, "Another Way of Thinking: A Review of Mathematical Models of Crime," 2013. 